\title{
Design of Experimental Platform for the Static Stiffness of Guide Roller
}

\author{
Yihua $\mathrm{Li}^{1}{ }^{1, a}$, Jianjian Xue ${ }^{1}$, Xin Zhang $^{1}$,Jianwei Song ${ }^{1}$,Huawei Jing ${ }^{1}$, Anhang Zhu and Lei Lin ${ }^{1}$ \\ ${ }^{1}$ School of Mechanical Engineering,Anhui University of Science and Technology, Huainan Anhui 232001,china
}

\begin{abstract}
In mine shaft hoisting system, The hoisting container generally adopts the guide roller which is used as the movement guiding device. Stiffness parameters and characteristic curves are very important technical indexes of the guide roller. For guide roller series, Proposing The method of stiffness performance test, Designing the experimental platform for the stiffness of the guide roller, The main functions of the experimental platform and the structure of the main units are analyzed. Results show that equipment can meet the stiffness test of the guide roller series, so as to determine the optimum stiffness value of the guide roller. Achieving the purpose of improving the life of guide roller.
\end{abstract}

\section{Introduction}

The guide roller is installed in shaft lifting container along the guide device running under stable tank on the road and it is one of the main components of the lifting container.On the one hand, it is used as a guide wheel running along the tank, and on the other hand, it can be connected with the lifting container and the tank, and transfer the horizontal force between them. The roller can also bear the lateral impact and vibration caused by the deviation of the shaft, the lack of the straight channel, the step of the joint and the vibration of the wire rope. Therefore, the guide roller is an important device which directly affects the safety and efficiency of the lifting container, and is interaction of media between shaft lifting container and shaft equipment, The stiffness parameter has a very important effect on the quality of the rigid equipment[1].

\section{Structure and stiffness of elastic guide roller}

The geometrical structure of guide roller is closely related to its mechanical properties, which directly affects the load distribution and stiffness of wheel ear. Therefore, the guide roller for the mechanical properties of the study, first of all need to master its structural features.

\subsection{Elastic guide roller}

The high speed shaft system generally adopts elastic guide roller, It has good cushioning and damping performance, and rigid collision between container and tank can be avoided. Elastic guide roller only

\footnotetext{
a Yihua Li,JiangxiNanchang,associate professor.email:825857694@qq.com
} 
multiplies to prolong the service life of the container and tank, but also greatly improved the state of shaft hoist. So that the container running smoothly and no noise.For large scale hoisting containers for high speed operation, especially for high quality guide roller. The development of elastic roller ear is closely related to the use and development of rectangular cross section[2].At present, commonly used elastic guide roller are mainly L type guide roller, As shown in Figure 1.

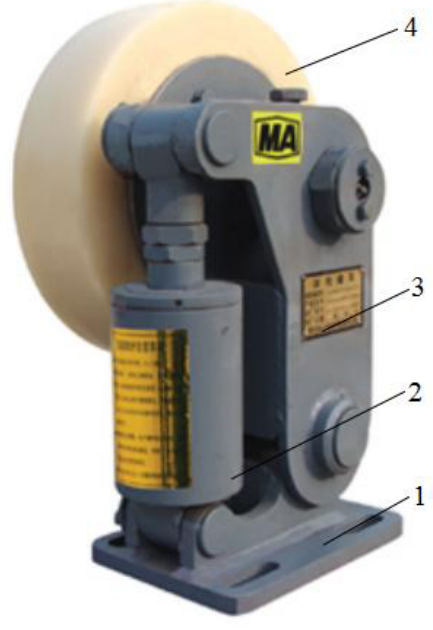

1-base 2-buffer 3-Bracket 4-roller

Figure 1. The structure of guide roller

\subsection{Stiffness performance of guide roller}

The guide roller is mainly composed of four parts: the base, the buffer, the bracket and the roller. The roller is made of polyurethane material, the disk spring element is adopted in the buffer, most of the impact force can be transmitted to the buffer device when the tank ear is subjected to lateral impact, and the vibration time delay will be transmitted to the damping device[3].

Mine shaft lifting container system generally adopts the guide roller as motion guiding device, its stiffness and stiffness characteristics is a very important index of the guide roller. If it is just too large, the ability of absorbing vibration is weakened, The vibration of the lifting container is intensified in the process of running along the tank is guided by the guide roller, lifting containers, tanks and roller cage body is subject to dynamic load increases, the probability of early failure or damage is increased, If the stiffness is too small the deformation of the roller ear is too large, the probability of contact between the container body and the tank is increased so as to increase the probability of failure or damage of the container and the tank ahead of time, lift system security is reduced[4].

In order to increase the service life of the guide roller and improve its stiffness characteristics, it is necessary to carry out the stiffness test of the guide roller, and get the stiffness parameter and the characteristic curve. Therefore, the design of the experiment platform of the guide roller stiffness is imminent, and the reasonable structure design and the selection of the components are the key to the design of the experimental platform[5].

\section{Structural design of experimental platform for the stiffness of the guide roller}

\subsection{The design hydraulic system}


Hydraulic loading system includes oil cylinder, manual pump, pipe joint hydraulic accessories, etc. The hydraulic loading system provides a key driving force for the design of the experimental platform. When the handle of the upper and the lower manual pumps makes the oil cylinder enter the oil, the pressure of the oil inlet cavity of the oil cylinder is larger, and the guide rod moves back and forth,the pressure head of the guide rod tightly presses the roller, the handle of the manual pump is continuously pressed, and the pressure of the roller is also increasing.Hydraulic power system provides different pressure, it is the core of the whole experimental platform[6].

Hydraulic cylinder is a hydraulic actuator can be converted into mechanical energy and reciprocating linear motion of the implementation of components.It has the advantages of simple structure, reliable operation, stable movement, flexible arrangement and high efficiency,and is widely used in various hydraulic systems.In the design of the experimental platform, the selection of the oil cylinder is very important. The basic parameters of the guide rollers are shown in Table 1.

Table 1. The basic parameters of the guide roller

\begin{tabular}{cccccc}
\hline Model & $\begin{array}{c}\text { roller diameter } \\
\text { /mm }\end{array}$ & $\begin{array}{c}\text { Max horizontal force } \\
\text { /KN }\end{array}$ & $\begin{array}{c}\text { Center height } \\
/ \mathrm{mm}\end{array}$ & $\begin{array}{c}\text { Cushioning device } \\
\text { stiffness KN/mm }\end{array}$ & $\begin{array}{c}\text { Buffer } \\
\text { trip/mm }\end{array}$ \\
\hline L20 & 200 & 8 & 240 & $0.29 \sim 0.32$ & $15 \sim 18$ \\
L25 & 250 & 12 & 260 & $0.43 \sim 0.48$ & $15 \sim 18$ \\
L30 & 300 & 16 & 320 & $0.57 \sim 0.64$ & $15 \sim 18$ \\
L35 & 350 & 24 & 320 & $0.86 \sim 0.96$ & $15 \sim 18$ \\
L42.5 & 420 & 32 & 320 & $1.0 \sim 1.12$ & $15 \sim 18$ \\
\hline
\end{tabular}

$\mathrm{L}$ represents the type, and the following number represents the diameter of the roller.Table 1 shows that the maximum horizontal forces of different guide rollers are different.Therefore, the maximum output power of the designed cylinder is more than $32 \mathrm{KN}$, and the working stroke of the buffer device is more than $18 \mathrm{~mm}$. The main parameters of the cylinder are calculated as shown in Table 2.

One way manual oil pump is a kind of small hydraulic pump station, which can convert manual mechanical energy into hydraulic energy. The manual oil pump is composed of six parts: the pump body, the handle part, the hose part, the storage tank valve and the pressure gauge. This experiment platform uses the SYB-2 series manual oil pump.

Table 2. The main parameters of the cylinder

\begin{tabular}{cccccc}
\hline $\begin{array}{c}\text { Pressure } \\
/ \mathrm{MPa}\end{array}$ & $\begin{array}{c}\text { Internal } \\
\text { diameter } \\
/ \mathrm{mm}\end{array}$ & $\begin{array}{c}\text { Piston rod } \\
\text { diameter } / \mathrm{mm}\end{array}$ & $\begin{array}{c}\text { wall } \\
\text { thickness } \\
/ \mathrm{mm}\end{array}$ & $\begin{array}{c}\text { Cylinder bottom } \\
\text { thickness } / \mathrm{mm}\end{array}$ & $\begin{array}{c}\text { Working } \\
\text { stroke/mm }\end{array}$ \\
\hline 3.5 & 100 & 50 & 2.18 & 12.49 & 40 \\
\hline
\end{tabular}

\subsection{The design of high modulation system}

In order to adjust the cylinder head to the center position of the guide roller, this experiment table uses the worm gear screw rod elevator, the worm gear screw lifter has the advantages of large transmission ratio, compact structure, stable operation, low noise and can not be used for other auxiliary mechanisms that can be obtained through the transfer of anti stroke self-locking. As can be seen from table 1, the center of the cylinder is different from each other, and the worm gear is used to transfer the oil cylinder to the right position in order to apply pressure to the cylinder ear.It not only improves the accuracy of the experimental platform, but also improves the efficiency of the experiment. The center height of the guide roller is shown in Figure 2. 


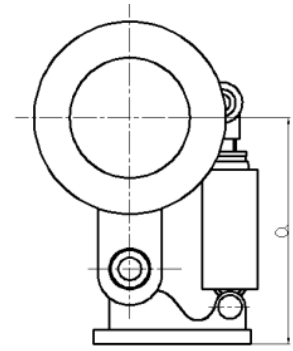

Figure 2. The center height of the guide roller

In order to achieve the cylinder head can move up and down the oil cylinder to be fixed on the flange, flange and linear guide rail are connected by bolt.By adjusting the worm wheel screw rod by hand wheel,by adjusting the worm gear screw rod elevator by hand wheel,the worm wheel elevator controls the pressure head to move up and down in the guide rail to ensure that the pressure head is aligned with the center of the guide roller,the manual pump is used to pressurize the oil cylinder to push the pressure head to exert pressure on the guide roller.

\subsection{The design of measurement system}

The measuring system comprises a digital display meter, a pressure sensor and a displacement sensor, A pressure sensor is a sensor that converts pressure into electrical signal output. The pressure sensor is generally composed of elastic sensitive element and displacement sensing element. The function of the elastic sensing element is to make the measured pressure acting on a certain area and convert it into a displacement or strain, and then convert the displacement sensitive element or strain gauge into an electrical signal which is related to the pressure. The pressure sensor is made of stainless steel components, imported elastomer original, with high sensitivity, stable performance, good impact resistance.

Displacement sensor, also known as linear sensor, is a kind of linear device belonging to metal induction, the function of the sensor is to convert the measured physical quantities into electricity. The experimental platform uses BWL pull rod displacement sensor. BWL pull rod displacement sensor effective stroke is $100 \mathrm{~mm}$, both ends have $3.5 \mathrm{~mm}$ buffer stroke, the accuracy of $0.08 \% \sim$ $0.04 \%$ FS.BWL displacement sensor using the world's leading nano chemical conductive materials and precious metal wear-resistant new materials, It features high precision, high linearity, long life. The pressure sensor is arranged at the end of the oil cylinder, and the pressure of the pressure head can be displayed when the oil cylinder is put into the oil. The BWL displacement sensor is installed on the flange of the oil cylinder, and the pull rod ball head of the displacement sensor is consistent with the position of the head of the oil cylinder. The measured displacement precision is high, and the numerical value is displayed on the displacement digital display table. Electrical control system does not solve the pressure and displacement measurement, but also improves the accuracy and efficiency of the entire experimental platform.

\section{Composition and structure of experiment platform}

\subsection{Composition of the experimental platform}

The experiment platform mainly consists of the frame body, the mounting seat, the hydraulic loading system, the height adjusting system, the testing system and so on. As shown in Figure 3.The structure of the experimental platform is consistent with the experiment of the stiffness of the guide roller. It not only has the reasonable structure design, but also has the optimal structure arrangement of the experimental platform, which saves a lot of materials and reduces the cost. Four wheels with brakes 
are installed on the base of the experimental platform, so that the handling of the experimental platform[7].

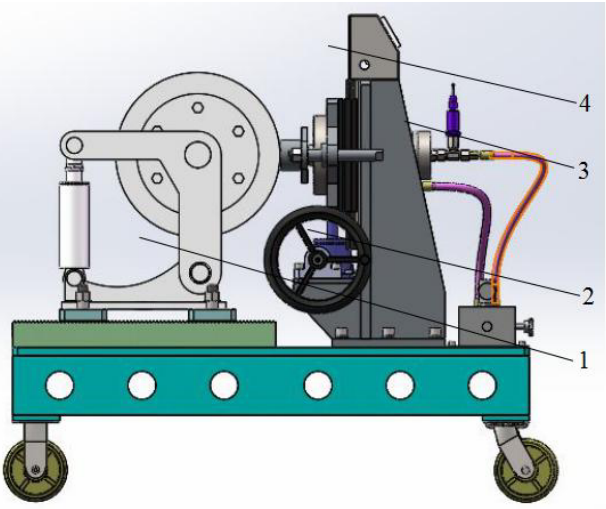

1-Roller cage ear 2-Handwheel 3-Pressure transducer 4-Digital display meter

Positive view

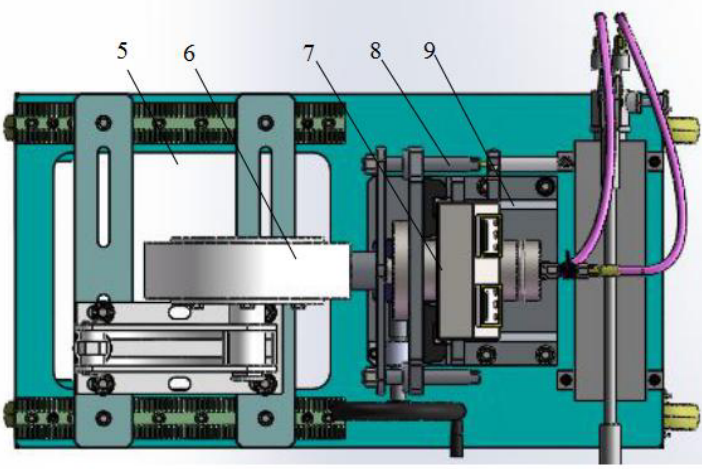

5-Mounting seat 6-Pressure head 7-Hydraulic cylinder

8-Displacement transducer 9-Manual pump

Top view

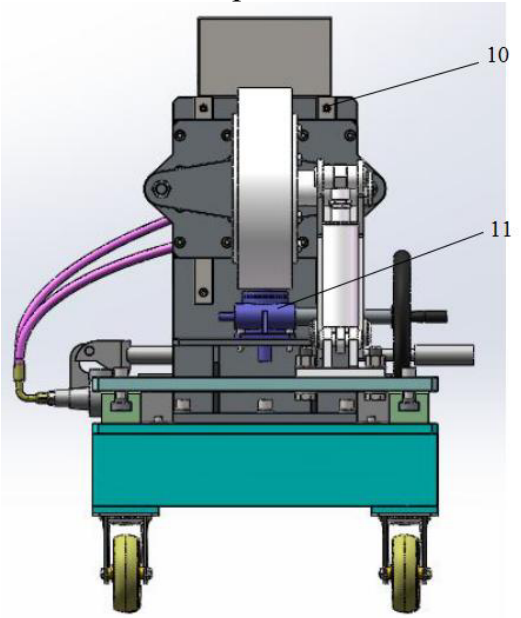

10-Linear guide rail 11 -Worm screw

Figure 3. Composition and structure of experiment platform 


\subsection{Composition of the experimental platform}

The main technical parameters are shown in Table 3.

Table 3: The main parameters of the cylinder

\begin{tabular}{cc}
\hline $\begin{array}{c}\text { The size of the experimental bench is } \\
\text { long, wide and high } \\
\text { /mm }\end{array}$ & 1100 X650X750 \\
\hline $\begin{array}{c}\text { T type groove track adjustable } \\
\text { range/mm }\end{array}$ & 560 \\
\hline $\begin{array}{c}\text { Hydraulic cylinder stroke } \\
\text { /mm }\end{array}$ & 80 \\
\hline $\begin{array}{c}\text { Maximum thrust of hydraulic } \\
\text { cylinder/KN }\end{array}$ & 100 \\
\hline $\begin{array}{c}\text { Worm screw rod height adjustment } \\
\text { range/mm }\end{array}$ & 400 \\
\hline $\begin{array}{c}\text { Manual pump rated pressure } \\
\text { /MP }\end{array}$ & $0-60$ \\
\hline $\begin{array}{c}\text { Hand pump the most big shake } \\
\text { force/N }\end{array}$ & 450 \\
\hline $\begin{array}{c}\text { Adjustable range of U type } \\
\text { groove/mm }\end{array}$ & 200 \\
\hline
\end{tabular}

Guide roller test bench is pushed to the right position,through the heavy fixed belt brake with brake casters and heavy duty casters will experiment fixed guide roller.The selection of the guide roller is hoisted on the mounting seat on the machine frame, and the position of the mounting seat is adjusted, and the mounting seat is fixed on the T groove rail by screws. There is a tooth surface on the $\mathrm{T}$ type slot rail, which increases the stability of the guide roller.Adjust the position of the guide roller and fix it with the bolt on the mounting seat.The mounting seat is provided with a waist shaped hole, which is convenient for the movement of the position of the guide roller. When the preparatory work is completed,horizontal force is applied to the guide roller .

\section{Acknowledgements}

This research is supported by the key project of natural science foundation for Anhui University (No.KJ2015ZD019).

\section{References}

1. XUE Jian-jian,LI Yi-hua,WANG Jing-wei.Shaft lifting application and development direction of the container roller cage ear[J].NEI JIANG KE JI,2016(8)39-40.

2. LIU Chun-feng,HAN Yan-wei.Structure analysis and development of roll guide shoes as vertical well hoisting installation[J].Coal Mine Machinery,2003(9):84-85.

3. FUN Ming-yuan,SUN Han-jing.Polyurethane elastomer and its application, Third Edition[M].BEIJING:Chemical Industry Press, 1994.

4. FAN YING,Mine hoisting machinery design[M].China University of Mining and Technology

5. press, 2000,12 .

6. QI Xiao-nan,QIN Qiang,ZHU Jia-cheng.Analysis of Guider Roller Stiffness Based On ANSYS[J].Coal Mine Machinery,2015,36(6):130-132.

7. QIN QIANG,ZHANG An-ning,YAN Hong-xin.Static stiffness test device of guide roller:China, ZL201505641209[P].2015-09-07 